Article

\title{
Acid-promoted Ir-La-S/AC-catalyzed methanol carbonylation on single atomic active sites
}

\author{
Zhou Ren a,c, Yuan Lyu a,*, Siquan Feng a,c, Xiangen Song a, Yunjie Ding a,b,\# \\ a Dalian National Laboratory for Clean Energy, Dalian Institute of Chemical Physics, Chinese Academy of Sciences, Dalian 116023, Liaoning, China \\ b State Key Laboratory of catalysis, Dalian Institute of Chemical Physics, Chinese Academy of Sciences, Dalian 116023, Liaoning, China \\ c University of Chinese Academy of Sciences, Beijing 100049, China
}

\section{A R T I C L E I N F O}

\section{Article history:}

Received 19 January 2018

Accepted 2 March 2018

Published 5 June 2018

\section{Keywords:}

Heterogeneous methanol carbonylation

Ir-La-S/AC catalyst

Bifunctional catalyst

Single-atomic active site

Co-impregnation

\begin{abstract}
A B S T R A C T
Highly active Ir-La-S/AC catalyst was successfully prepared by co-impregnation of an activated carbon (AC) carrier with a sulfuric acid solution of Ir and La species and compared with a traditionally prepared Ir-La/AC catalyst. High angle annular dark-field-scanning transmission electron microscopy (HAADF-STEM) measurement results show that most of the Ir species on Ir-La-S/AC exist as single atomic sites, while those on Ir-La/AC exist as nanoparticles with an average diameter of $1.5 \mathrm{~nm}$. Evaluation of Ir-La-S/AC as a catalyst for heterogeneous carbonylation of methanol to acetyl gave a maximum TOF (turn-over-frequency) of $2760 \mathrm{~h}^{-1}$, which was distinctly higher than that achieved by the Ir-La/AC catalyst (approximately $1000 \mathrm{~h}^{-1}$ ). Temperature-programmed desorption of ammonia ( $\mathrm{NH}_{3}$-TPD) result shows that the addition of sulfuric acid during the preparation procedure results in significantly more acidic sites on Ir-La-S/AC than those on Ir-La/AC, which plays a key role in the enhancement of CO insertion as the rate-determining step. Temperature-programmed reduction (TPR) and in situ X-ray photoelectron spectroscopy reveal that Ir species are more reducible, and that more Ir ${ }^{+}$might be formed by activation of Ir-La-S/AC than those on the Ir-La/AC catalyst, which is thought to be beneficial for reductive elimination of AcI from $\mathrm{Ir}^{3+}$ species as an essential step for $\mathrm{CH}_{3} \mathrm{I}$ regeneration and acetyl formation.
\end{abstract}

(C) 2018, Dalian Institute of Chemical Physics, Chinese Academy of Sciences. Published by Elsevier B.V. All rights reserved.

\section{Introduction}

The active metal components on supported heterogeneous catalysts prepared by the impregnation method generally exist in cluster forms [1,2], leading to lower catalytic efficiency relative to the corresponding homogeneous catalysts. In particular, in the case of supported noble-metal catalysts, significant efforts have been made to obtain single atomic dispersity [3-8] to replace the corresponding homogeneous catalysts, which are usually difficult to separate from products $[9,10]$. Another challenge comes from the use of liquid acids in some acid-catalyzed homogeneous processes. Solid acidic catalysts are being widely studied [11-13] in efforts to reduce environmental pollution and the corrosion of devices caused by the use of liquid acids. For instance, $\mathrm{H}_{2} \mathrm{SO}_{4} / \mathrm{AC}$ catalysts prepared by modification of activated carbon (AC) with sulfuric acid have been found to be effective in the catalytic esterification process $[11,14]$ as a replacement for liquid sulfuric acid.

It is well-known that the dispersive states of catalytic active species on a support are related to the properties of the pre-

\footnotetext{
* Corresponding author. Tel: +86-411-84379601; Fax: +86-411-84379143; E-mail: luyuan@dicp.ac.cn

\# Corresponding author. Tel/Fax: +86-411-84379143; E-mail: dyj@dicp.ac.cn

This work was supported by the National Key R\&D Program of China (2017YFB0602203).

DOI: 10.1016/S1872-2067(18)63019-0 | http://www.sciencedirect.com/science/journal/18722067 | Chin. J. Catal., Vol. 39, No. 6, June 2018
} 
cursor, and the support surface, and the loading technique. Among these, it has been recognized that the property of the support surface [15] is one of the most critical factors. In order to obtain better dispersity, pre-treatment of the support surface is usually needed. The interaction of the supported components with the support surface might be strengthened by regulating the hydrophilicity or hydrophobicity of the surface so as to change the dispersity of the supported active species [16-19]. For instance, $\mathrm{Rh}$ on $\mathrm{SiO}_{2}$ can be dispersed into smaller particles by modification of the $\mathrm{SiO}_{2}$ surface with suitable organic reagents [20-23]. AC is widely used as a support for catalysts, but its surface is generally composed of hydrophobic micro-graphite crystallites [24], which usually lead to unsatisfactory dispersity of the loaded components when selecting a polar solvent in the impregnation process. We hypothesize that modification of an AC surface by sulfuric acid during the impregnation process might offer a possibility to improve metal dispersity on an AC surface.

Additionally, some reactions, such as methanol carbonylation [25-27], can be catalyzed by metal-acid bifunctional catalyst systems [28,29]. It has been found that sulfuric acid [30] can act as a promoter to improve the activity of a homogeneous Ir-catalyzed methanol carbonylation system [31-33]. Therefore, a heterogeneous catalyst with single atomic dispersed Ir sites accompanied by suitable acidic sites might have the potential to replace the corresponding homogeneous system.

Research by the Eastman Chemical Company has shown the effectiveness of the Ir-La/AC catalyst, which has proved to be active for vapor-phase heterogeneous methanol carbonylation. A mechanism of reaction over Ir-La/AC catalyst was proposed by Kwak et al. [34-36]. to explain the model of molecular active sites, as well as the promotional effect of La species acting as Lewis acids to accelerate CO insertion as the rate-limiting step. In addition, it is commonly assumed that the $\mathrm{Ir}^{+}$species, which is reduced from $\mathrm{Ir}^{3+}$, is the real active center of methanol carbonylation in the formation of coordination complexes.

Because AC-supported sulfuric acid can act as an acid catalyst, we prepared a sulfuric-acid-promoted Ir-La-S/AC catalyst by doping the impregnation solution with sulfuric acid. The assistive effect of the acid on carbonylation of methanol to form acetyl and the dispersity of active $\mathrm{Ir}^{+}$sites were investigated in this paper.

\section{Experimental}

\subsection{Reagent}

The activated carbon (Brunauer-Emmett-Teller (BET) surface area $1300 \mathrm{~m}^{2} / \mathrm{g}$ ) was purchased from the Tangshan United Carbon Technology Co., Ltd., China. The iridium trichloride (Ir $>58 \%$ ) was purchased from the Shanghai Jiuling Chemical Company, China. The lanthanum oxide (>99.9\%) was purchased from the Aladdin Company Co., Ltd, China. The concentrated sulfuric acid ( $>98 \%$ ) was purchased from the Tianjin Kemiou Chemical Reagent Co., Ltd. The hydrochloric acid $(>37 \%$ ) was purchased from Beijing Chemical Works, China. All reagents of analytical grade were used as purchased without further purification, unless otherwise stated. The aqueous solution of sulfuric acid was prepared by dilution of $20.8 \mathrm{~g}$ of concentrated sulfuric acid with deionized water in a $100-\mathrm{mL}$ volumetric flask.

\subsection{Preparation of catalysts}

The preparation of Ir-La/AC was similar to the process reported by Kwak et al. [34]. First, $0.0862 \mathrm{~g}$ of $\mathrm{IrCl}_{3}$ was dissolved in $17.16 \mathrm{~g}$ of deionized water at $65^{\circ} \mathrm{C}$. Then, $0.0428 \mathrm{~g}$ of $\mathrm{La}_{2} \mathrm{O}_{3}$ and $1 \mathrm{~mL}$ of $37 \% \mathrm{HCl}$ were added to the solution, and it was continuously stirred until the $\mathrm{La}_{2} \mathrm{O}_{3}$ was dissolved. Moreover, 5 $\mathrm{g}$ of AC was added to the precursor solution and dried at $65{ }^{\circ} \mathrm{C}$ for $6 \mathrm{~h}$. The catalyst was fully dried at $120^{\circ} \mathrm{C}$ for $12 \mathrm{~h}$. The dried catalyst was calcined at $280{ }^{\circ} \mathrm{C}$ for $4 \mathrm{~h}$ in flowing $\mathrm{Ar}$ to obtain the final catalyst (denoted Ir-La/AC).

Ir-La-1\%S/AC, Ir-La-5\%S/AC, Ir-La-10\%S/AC, Ir-La$20 \% \mathrm{~S} / \mathrm{AC}$, and $\mathrm{Ir}-\mathrm{La}-40 \% \mathrm{~S} / \mathrm{AC}$ catalysts were prepared by co-impregnation of AC carrier with sulfuric acid solutions of $\mathrm{IrCl}_{3}$ and $\mathrm{La}_{2} \mathrm{O}_{3}$, and $1 \% \mathrm{~S}, 2 \% \mathrm{~S}, 10 \% \mathrm{~S}, 20 \% \mathrm{~S}$ and $40 \% \mathrm{~S}$ indicated the initial amounts of $\mathrm{S}$ added to the precursors of Ir-La-S/AC catalysts. A typical preparation of Ir-La-20\%S/AC catalyst, as an example, proceeded as follows. First, $0.0862 \mathrm{~g}$ of $\mathrm{IrCl}_{3}$ was dissolved in $17.16 \mathrm{~g}$ of deionized water at $65^{\circ} \mathrm{C}$. Then, $0.0428 \mathrm{~g}$ of $\mathrm{La}_{2} \mathrm{O}_{3}$ and $15 \mathrm{~mL}$ of sulfuric acid solution $(2.08$ mol/L) were added to the solution, and it was continuously stirred until the $\mathrm{La}_{2} \mathrm{O}_{3}$ was dissolved. $5 \mathrm{~g}$ of $\mathrm{AC}$ were then added to the solution and dried at $120^{\circ} \mathrm{C}$ for $12 \mathrm{~h}$ to obtain the precursor of the catalyst, followed by calcination at $280{ }^{\circ} \mathrm{C}$ for $4 \mathrm{~h}$ in flowing Ar to obtain Ir-La-20\%S/AC. The $20 \% \mathrm{~S} / \mathrm{AC}$ catalyst was also prepared for comparison without the addition of $\mathrm{IrCl}_{3}$ and $\mathrm{La}_{2} \mathrm{O}_{3}$.

\subsection{Characterization}

Scanning electron microscopy (SEM) and energy dispersive spectrometer (EDS) mapping were performed on a JSM-7800F scanning electron microscope (made in Japan Electronics Co., Ltd.). The transmission electron microscopy (TEM) study was performed on a JEM-2100 transmission electron microscope. HAADF-STEM was performed on a JEM-ARM200F. The Ir-La/AC and Ir-La-20\%S/AC catalysts were activated by syngas $\left(\mathrm{CO} / \mathrm{H}_{2}=10\right)$ at $34 \mathrm{~mL} / \mathrm{min}$ for $1 \mathrm{~h}$ at $235^{\circ} \mathrm{C}$ and $2.5 \mathrm{MPa}$ before the SEM, TEM, and high angle annular dark-field-scanning transmission electron microscopy (HAADF-STEM) measurements.

The X-ray diffraction (XRD) phase analysis of Ir-La-S/AC and Ir-La/AC was performed with a PANalytical X'Pert ${ }^{3}$ powder diffractometer using $\mathrm{Cu} K \alpha$ radiation at $40 \mathrm{kV}$ and $40 \mathrm{~mA}$ in a scanning-angle $(2 \theta)$ range of $5^{\circ}-90^{\circ}$ at a speed of $7^{\circ} / \mathrm{min}$.

Temperature-programmed reduction of hydrogen ( $\mathrm{H}_{2}$-TPR) was performed on a Zeton Altramira AMI-300 apparatus $[37,38]$. Ir-La/AC or Ir-La-S/AC catalyst in the amount of $0.1 \mathrm{~g}$ was pretreated at $120^{\circ} \mathrm{C}$ for $1 \mathrm{~h}$ in a flow of He. After cooling to room temperature in a flow of $\mathrm{He}$, the temperature was increased to $800{ }^{\circ} \mathrm{C}$ at a heating rate of $10{ }^{\circ} \mathrm{C} / \mathrm{min}$ under a gas mixture $\left(10 \% \mathrm{H}_{2} / \mathrm{Ar}, 50 \mathrm{~mL} / \mathrm{min}\right)$. The TPR data were collected 
by a TCD detector. For quantification of total $\mathrm{H}_{2}$ evolution, the thermal conductivity detector (TCD) was calibrated with pulses of a mixture gas $\left(10 \% \mathrm{H}_{2} / \mathrm{Ar}\right)$. Exhaust gases were also analyzed by a Pfeiffer mass spectrometer $(m / z=2,16,18,28,34,44,64$, and 80).

In situ X-ray photoelectron spectroscopy (in situ XPS) analysis was carried out on a ThermoFisher ESCALAB 250Xi with Al $K_{\alpha}$ radiation. Ir-La/AC and Ir-La-20\%S/AC were pretreated by the mixed gas $\left(\mathrm{CO} / \mathrm{H}_{2} / \mathrm{He}=6: 0.6: 93.4\right)$ under atmospheric pressure at $235^{\circ} \mathrm{C}$ for $120 \mathrm{~min}$ in an XPS chamber, followed by XPS testing under vacuum without exposure to air. The binding energies were calibrated with the $\mathrm{C} 1 \mathrm{~s}$ level of adventitious carbon $(284.8 \mathrm{eV})$ as an internal standard reference.

Temperature-programmed desorption of ammonia (NH3-TPD) was performed on a Zeton Altramira AMI-300 apparatus $[37,39]$. Catalyst in the amount of $0.09 \mathrm{~g}$ was pretreated at $120^{\circ} \mathrm{C}$ for $1 \mathrm{~h}$ in a flow of He. After cooling to room temperature under a He atmosphere, the catalyst was heated to $235^{\circ} \mathrm{C}$ at a rate of $3.3^{\circ} \mathrm{C} / \mathrm{min}$ and held for $1 \mathrm{~h}$ under a syngas mixture $\left(\mathrm{CO} / \mathrm{H}_{2}=10 / 1,50 \mathrm{~mL} / \mathrm{min}\right)$ and was then cooled to 50 ${ }^{\circ} \mathrm{C}$. The catalyst was purged with $\mathrm{He}$ for $1 \mathrm{~h}$ at $50{ }^{\circ} \mathrm{C}$. After purging with a mixture gas $\left(10 \% \mathrm{NH}_{3} / \mathrm{He}, 50 \mathrm{~mL} / \mathrm{min}\right)$ for $2 \mathrm{~h}$ at $50{ }^{\circ} \mathrm{C}$, the catalyst was treated in a flow of He for $1 \mathrm{~h}$ to remove any physically adsorbed $\mathrm{NH}_{3}$. Then, the temperature was increased to $800{ }^{\circ} \mathrm{C}$ at a heating rate of $10{ }^{\circ} \mathrm{C} / \mathrm{min}$ in a flow of $\mathrm{He}(50 \mathrm{~mL} / \mathrm{min})$ and maintained at $800{ }^{\circ} \mathrm{C}$ for $30 \mathrm{~min}$. The desorbed $\mathrm{NH}_{3}$ was detected online by TCD. For quantification of total $\mathrm{NH}_{3}$ evolution, the TCD spectra were calibrated with pulses of a mixture gas $\left(10 \% \mathrm{NH}_{3} / \mathrm{He}\right)$. Exhaust gases were also analyzed by a Pfeiffer mass spectrometer $(\mathrm{m} / \mathrm{z}=17,16,28$, and 44).

Acid-base titration [11,40-42] was tested as follows: $0.05 \mathrm{~g}$ of catalyst was added to $15 \mathrm{ml}$ of an aqueous $\mathrm{NaCl}$ solution (1 mol/L) overnight. Then, several drops of phenolphthalein ethanol solution were added, and the catalyst was acid-base-titrated with a $\mathrm{NaOH}$ solution $(0.02 \mathrm{~mol} / \mathrm{L})$.

Inductively coupled plasma (ICP) measurements were taken with a PerkinElmer apparatus (NexION 300D). As a typical run, $0.50 \mathrm{~g}$ of collected liquid sample was diluted in $50 \mathrm{~mL}$ of deionized water before ICP-MS (Inductively coupled plasma mass spectrometry) testing.

X-ray fluorescence (XRF) testing was performed on a Magix apparatus (Philips Corp.). As a typical run, $0.11 \mathrm{~g}$ of catalyst sample was ground to powder, mixed with $2.40 \mathrm{~g} \mathrm{H}_{3} \mathrm{BO}_{3}$, and tableted.

\subsection{Evaluation}

Methanol carbonylation tests on Ir-La/AC and Ir-La-S/AC were conducted in a continuous-flow Hastelloy-made facility, including a fixed-bed reactor with an inner diameter of $6 \mathrm{~mm}$. According to our previous study, because the blended hydrogen can be a stabilizer of carbonylation by inhibition of carbon deposition originating from methanol or $\mathrm{CO}$, syngas $\left(\mathrm{CO} / \mathrm{H}_{2}=\right.$ 10) instead of pure $\mathrm{CO}$ was selected as a reagent. Catalyst in the amount of $0.21 \mathrm{~g}$ was pretreated by syngas $\left(\mathrm{CO} / \mathrm{H}_{2}=10\right)$ at 34 $\mathrm{mL} / \mathrm{min}$ for $1 \mathrm{~h}$ at $235^{\circ} \mathrm{C}$ and $2.5 \mathrm{MPa}$. Then, a premixed liquid solution of methanol and methyl iodide $(\mathrm{MeOH} / \mathrm{MeI}=8 / 1$ wt $\%$ ) was introduced into the reactor by a liquid pump at a rate of $0.04 \mathrm{~mL} / \mathrm{min}$. Methanol and methyl iodide were vaporized by quartz sand packing upper layers in the reactor. The liquid product was collected by a condenser at $3{ }^{\circ} \mathrm{C}$. The tail gas was analyzed online using an Agilent $7890 \mathrm{~A}$ gas chromatograph equipped with a Porapak-QS column and a TCD detector. The liquid products were analyzed offline using an Agilent 7890A gas chromatograph equipped with an FID (flame ionization detector) and an FFAP (free fatty acid phase) column using isobutyl alcohol as an internal standard.

$$
\begin{aligned}
& \text { Conversion }=\frac{n_{\mathrm{CH}_{3} \mathrm{COOH}}+2 n_{\mathrm{CH}_{3} \mathrm{COOCH}_{3}}+n_{\mathrm{CH}_{4}}}{n_{\mathrm{CH}_{3} \mathrm{OH}}} \\
& \mathrm{TOF}_{\text {acetyl }}=\frac{n_{\mathrm{CH}_{3} \mathrm{COOH}}+n_{\mathrm{CH}_{3} \mathrm{COOCH}_{3}}}{n_{\mathrm{Ir}} \times t} \\
& \text { Selectivity } \mathrm{CH}_{3} \mathrm{COOH}=\frac{n_{\mathrm{CH}_{3} \mathrm{COOH}}}{n_{\mathrm{CH}_{3} \mathrm{COOH}}+2 n_{\mathrm{CH}_{3} \mathrm{COOCH}_{3}}+n_{\mathrm{CH}_{4}}} \\
& \text { Selectivity }{ }_{\mathrm{CH}_{3} \mathrm{COOCH}_{3}}=\frac{2 n_{\mathrm{CH}_{3} \mathrm{COOCH}_{3}}}{n_{\mathrm{CH}_{3} \mathrm{COOH}}+2 n_{\mathrm{CH}_{3} \mathrm{COOCH}_{3}}+n_{\mathrm{CH}_{4}}} \\
& \text { Selectivity }{ }_{\mathrm{CH}_{4}}=\frac{n_{\mathrm{CH}_{4}}}{n_{\mathrm{CH}_{3} \mathrm{COOH}}+2 n_{\mathrm{CH}_{3} \mathrm{COOCH}_{3}}+n_{\mathrm{CH}_{4}}}
\end{aligned}
$$

$n_{\mathrm{CH}_{3} \mathrm{OH}}$ : total molar concentration of added $\mathrm{CH}_{3} \mathrm{OH}$.

$n \mathrm{CH}_{3} \mathrm{COOH}$ : the molar concentration of $\mathrm{CH}_{3} \mathrm{COOH}$ after reaction.

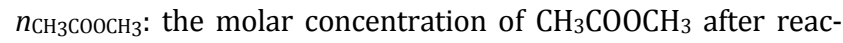
tion.

$n_{\mathrm{CH}_{4}}$ : the molar concentration of $\mathrm{CH}_{4}$ after reaction.

$t(\mathrm{~h})$ : time on stream.

\section{Results and discussion}

\subsection{Characterization of catalysts}

\subsubsection{SEM, TEM, and HAADF-STEM characterization}

Ir-La/AC and Ir-La-20\%S/AC catalysts activated with syngas (CO: $\mathrm{H}_{2}=10: 1,235^{\circ} \mathrm{C}, 1 \mathrm{~h}$ ) were measured using SEM, TEM, and
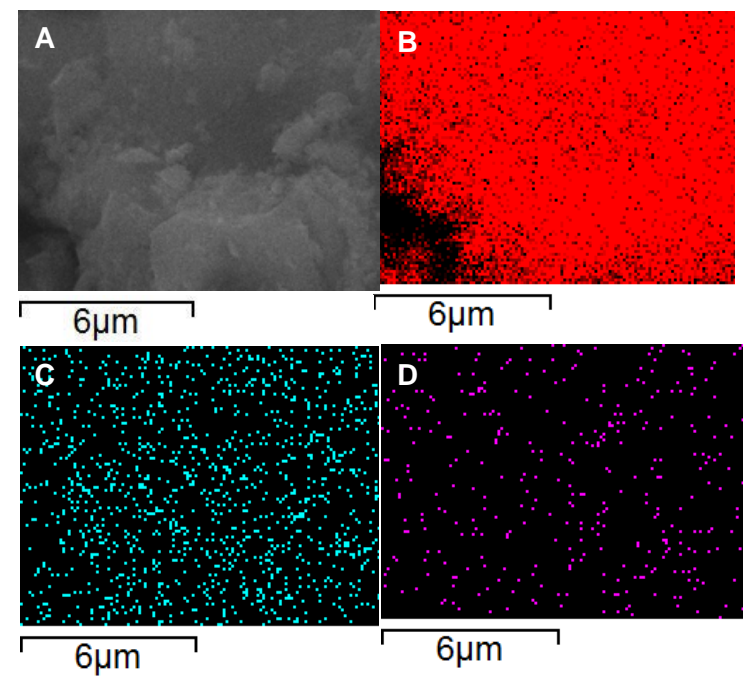

Fig. 1. SEM image (A) and EDS-mapping of C (B), La (C) and Ir (D) of activated Ir-La/AC catalyst. 


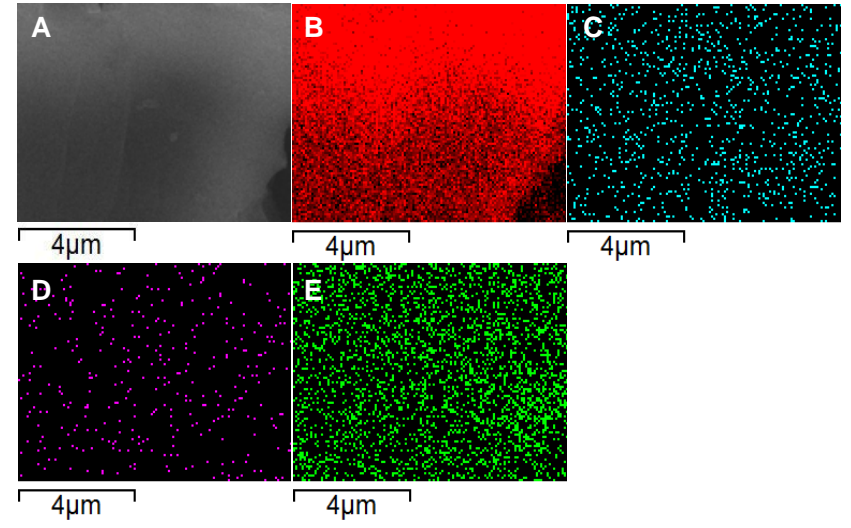

Fig. 2. SEM image (A) and EDS-mapping of C (B), La (C), Ir (D) and S (E) of activated Ir-La-20\%S/AC catalyst.

HAADF-STEM techniques to clarify the dispersive states of catalytic species over AC supports. SEM EDS mapping of activated Ir-La/AC and Ir-La-20\%S/AC samples are shown in Fig. 1 and 2 , respectively, indicating uniform distribution of the loaded elements in the catalysts. The XRD patterns (Fig. 3) of the two catalysts show that there are no obvious characteristic peaks assigned to crystalline phases of La, Ir, or S species in activated Ir-La/AC and Ir-La-20\%S/AC catalysts. Additionally, a few suspected particles of supported elements seem to exist in activated Ir-La/AC as revealed by TEM measurements at $2 \mathrm{~nm}$ resolution and shown in Fig. 4(A). No obvious nanoparticle is observed on TEM images of activated Ir-La-20\%S/AC catalysts (Fig. 4(B)), which means that La and Ir species on activated Ir-La-20\%S/AC are more uniformly dispersed. The HAADF-STEM images in Fig. 5 show the dispersity of Ir over activated Ir-La/AC and Ir-La-20\%S/AC at atomic resolution. The bright spots are identified as Ir or La species in activated Ir-La/AC and Ir-La-20\%S/AC catalysts. It is obvious that the loaded components on activated Ir-La-20\%S/AC disperse more uniformly than those on activated Ir-La/AC catalyst, which means that $\mathrm{S}$ species might enhance the dispersion of Ir and La on activated Ir-La-20\%S/AC. The bright spots of Ir-La-20\%S/AC are less than $0.5 \mathrm{~nm}$ in size, which implies that

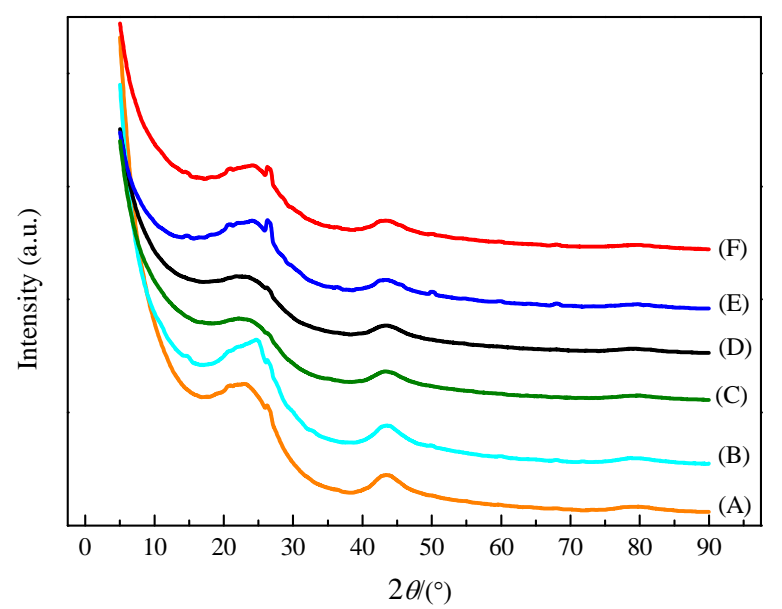

Fig. 3. XRD patterns of AC (A), 20\%S/AC (B), Ir-La/AC (C), the activated Ir-La/AC (D), Ir-La-20\%S/AC (E) and the activated Ir-La-20\%S/AC (F) samples.

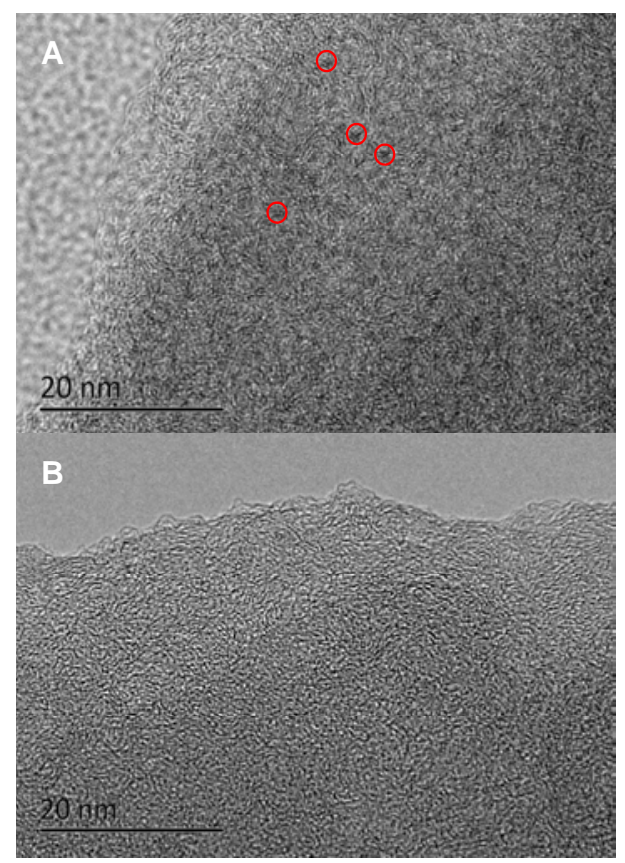

Fig. 4. TEM images of the activated Ir-La/AC (A) and Ir-La-20\%S/AC (B) catalysts.

the active sites of activated Ir-La-20\%S/AC might be in the form of single atomic states, while those on activated Ir-La/AC exist as nanoparticles or clusters with an average diameter of approximately $1.5 \mathrm{~nm}$. It can be concluded that the addition of sulfuric acid in the impregnation procedure of Ir-La-20\%S/AC catalyst changes the framework or surface polarity of AC to some extent [12].

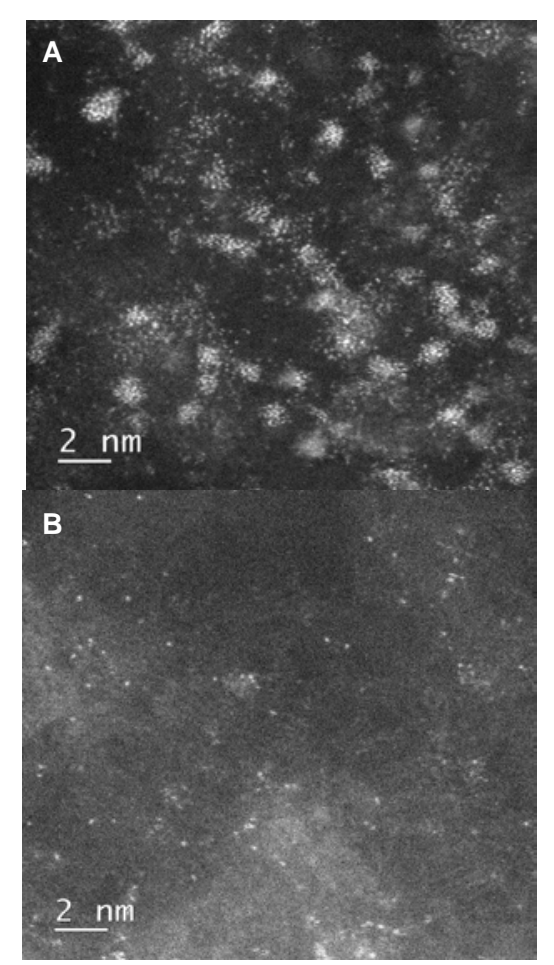

Fig. 5. HAADF-STEM images of the activated Ir-La/AC (A) and Ir-La-20\%S/AC (B) catalysts. 


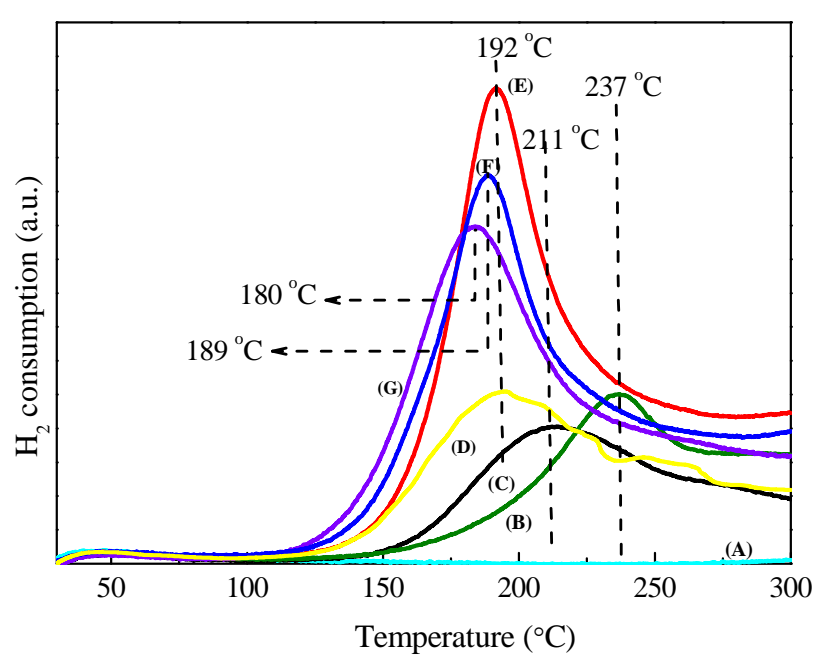

Fig. 6. $\mathrm{H}_{2}$-TPR profiles of $20 \% \mathrm{~S} / \mathrm{AC}$ (A), Ir-La/AC (B), Ir-La-1\%S/AC (C), Ir-La-2\%S/AC (D), Ir-La-10\%S/AC (E), Ir-La-20\%S/AC (F) and Ir-La-40\%S/AC (G) catalysts.

\subsection{2. $H_{2}$-TPR and in situ XPS}

$\mathrm{H}_{2}$-TPR was used to characterize the reducibility of Ir-La/AC and Ir-La-S/AC catalysts. As shown in Fig. 6, in contrast to the main reduction peak of Ir-La/AC appearing at $237^{\circ} \mathrm{C}$, the peaks of Ir-La-S/AC appear at temperatures in the range $180-211^{\circ} \mathrm{C}$, and higher loading of sulfuric acid is conducive to lower reduction temperature. The TCD peaks of $\mathrm{H}_{2}$-TPR mentioned above are also verified as $\mathrm{H}_{2}$ signals by the mass spectrometer. It is well known in this field that $\mathrm{La}^{3+}$ species are difficult to reduce at temperatures lower than $300{ }^{\circ} \mathrm{C}$ [43], and no response in the range $0-270{ }^{\circ} \mathrm{C}$ in the $\mathrm{H}_{2}$-TPR of $20 \% \mathrm{~S} / \mathrm{AC}$ is observed. Thus, it is confirmed that the main reduction peaks of Ir-La/AC and Ir-La-S/AC at the range $180-240{ }^{\circ} \mathrm{C}$ should be assigned to the reduction of $\mathrm{Ir}^{3+}$ species, but not to those of $\mathrm{La}^{3+}$ and $\mathrm{SO}_{4}{ }^{2-}$ species. Furthermore, the amount of $\mathrm{H}_{2}$ consumed by the reduction of Ir-La-S/AC (Table 1) is much higher than that of Ir-La/AC catalyst, which means that most of the $\mathrm{Ir}^{3+}$ species is difficult to reduce over Ir-La/AC, and more activated $\mathrm{Ir}^{+}$species can be formed on Ir-La-S/AC than on Ir-La/AC at temperatures lower than $240{ }^{\circ} \mathrm{C}$, which is almost the same temperature that activates the catalysts by syngas before reaction tests. The $\mathrm{H}_{2}$-TPR results and HAADF-STEM images suggest that highly atomic dispersity of $\mathrm{Ir}^{3+}$ species on Ir-La-S/AC catalysts favor the reduction of Ir species.

In situ XPS was used to clarify the chemical states of Ir-La/AC and Ir-La-20\%S/AC under reaction conditions. The XPS spectra are shown in Fig. 7. Binding energies, full widths at

Table 1

$\mathrm{H}_{2}$ consumption capacity of Ir-La/AC and Ir-La-S/AC tested by $\mathrm{H}_{2}$-TPR.

\begin{tabular}{lc}
\hline Catalyst & $\mathrm{H}_{2}$ consumption amount capacity $(\mu \mathrm{mol} / \mathrm{g})$ \\
\hline Ir-La/AC & 127.89 \\
Ir-La-1\%S/AC & 337.37 \\
Ir-La-2\%S/AC & 381.07 \\
Ir-La-10\%S/AC & 390.18 \\
Ir-La-20\%S/AC & 527.20 \\
Ir-La-40\%S/AC & 586.06 \\
\hline
\end{tabular}
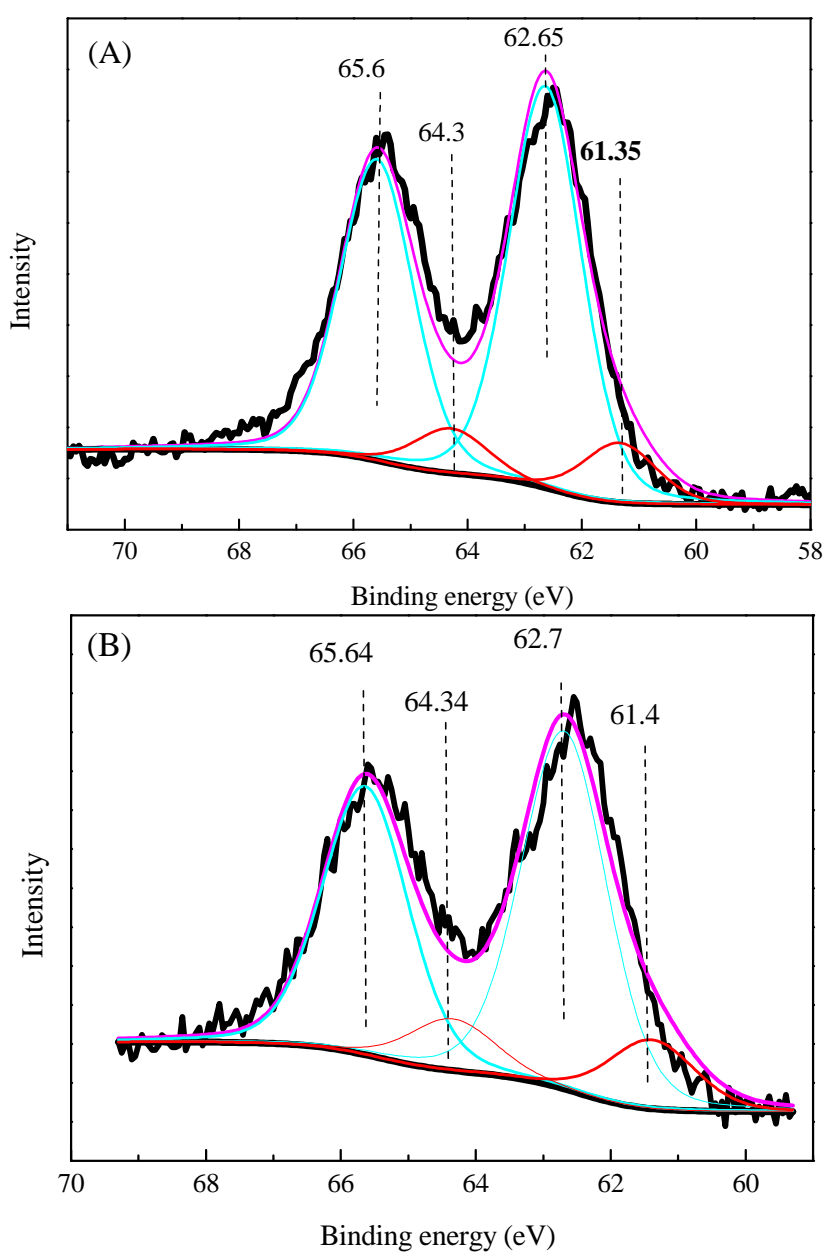

Fig. 7. Ir $4 f$ XPS spectra of activated Ir-La/AC catalyst (A) and Ir-La-20\%S/AC (B) catalysts.

Table 2

The comparison of binding energies, FWHMs, oxidation states, and area of Ir species between the activated Ir-La/AC and Ir-La-20\%S/AC.

\begin{tabular}{lccrlll}
\hline \multirow{2}{*}{ Catalyst } & \multicolumn{3}{c}{$\operatorname{Ir} 4 f_{7 / 2}$} & \\
\cline { 2 - 5 } & 62.65 & 1.5 & 1374 & $\mathrm{Ir}^{3+}$ & $\mathrm{Ir}^{3+} / \mathrm{Ir}^{+}=6.8$ \\
\hline Ir-La/AC & 61.35 & 1.5 & 203 & $\mathrm{Ir}^{+}$ & \\
& 62.70 & 1.5 & 803 & $\mathrm{Ir}^{3+}$ & $\mathrm{Ir}^{3+} / \mathrm{Ir}^{+}=5.1$ \\
Ir-La-20\%S/AC & 61.40 & 1.5 & 155 & $\mathrm{Ir}^{+}$ \\
\hline
\end{tabular}

half-maximums (FWHMs), oxidation states, and peak areas of $\mathrm{Ir}^{3+}$ and $\mathrm{Ir}^{+}$species obtained by in situ XPS are listed in Table 2. The binding energies of Ir $4 f_{7 / 2}$ appear at 62.7 and $61.35 \mathrm{eV}$, which are assigned to $\mathrm{Ir}^{3+}$ and $\mathrm{Ir}^{+}$species, respectively $[34,44]$. There is no doubt that only $\mathrm{Ir}^{3+}$ species exist in fresh Ir-La-20\%S/AC and Ir-La/AC. The XPS data in Table 2 show that the portion of $\mathrm{Ir}^{+}$species in the activated Ir-La-20\%S/AC $\left(\mathrm{Ir}^{3+} / \mathrm{Ir}^{+}=5.1\right)$ is greater than that in the activated Ir-La/AC $\left(\mathrm{Ir}^{3+} / \mathrm{Ir}^{+}=6.8\right)$, which illustrates that there are more active $\mathrm{Ir}^{+}$ species in the activated Ir-La-20\%S/AC sample. These results agree well with that of $\mathrm{H}_{2}$-TPR, indicating that $\mathrm{S}$ species mainly exist in the form of $-\mathrm{SO}_{3} \mathrm{H}$ [45] in Ir-La-S/AC, which accelerates the reduction of $\mathrm{Ir}^{3+}$ species to $\mathrm{Ir}^{+}$states.

\subsection{3. $\mathrm{NH}_{3}-\mathrm{TPD}$ and acid-base titration}




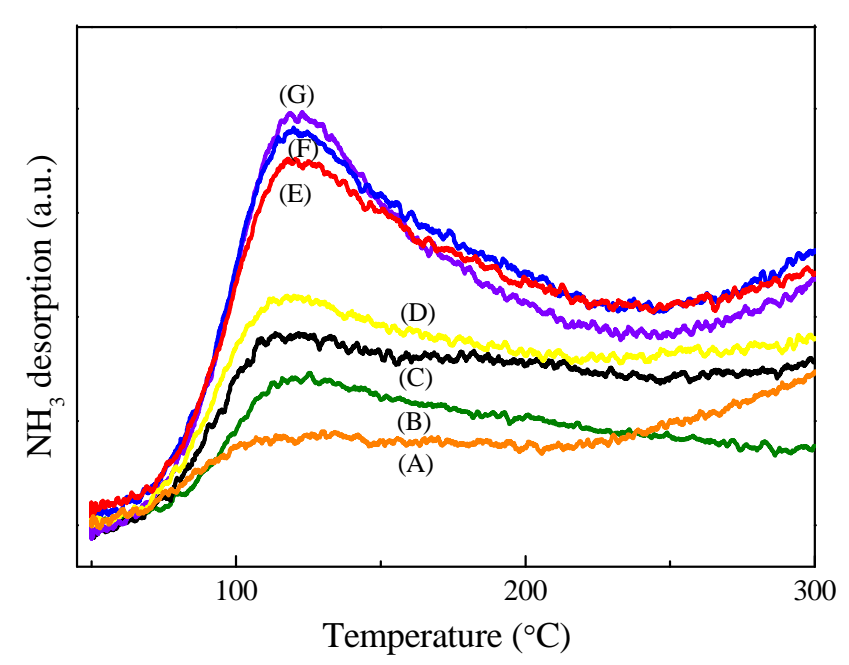

Fig. 8. $\mathrm{NH}_{3}-\mathrm{TPD}$ profiles of $\mathrm{AC}(\mathrm{A}), \mathrm{Ir}-\mathrm{La} / \mathrm{AC}(\mathrm{B}), \mathrm{Ir}-\mathrm{La}-1 \% \mathrm{~S} / \mathrm{AC}(\mathrm{C})$, Ir-La-2\%S/AC (D), Ir-La-10\%S/AC (E), Ir-La-20\%S/AC (F) and Ir-La- $40 \%$ S/AC (G) catalysts.

$\mathrm{NH}_{3}$-TPD was performed to characterize the acidity [46] of Ir-La/AC and Ir-La-S/AC samples with different $S$ contents. The $\mathrm{NH}_{3}$-TPD profiles are given in Fig. 8, and the acid capacities of the samples quantified by the peak area of $\mathrm{NH}_{3}$-TPD profiles are listed in Table 3, accompanied by those obtained by the acid-base-titration method. It has been confirmed by mass spectrometry that the TCD peaks of Ir-La-S/AC and Ir-La/AC at $120^{\circ} \mathrm{C}$ are assigned to the $\mathrm{NH}_{3}$ signal. According to Table 3 , the acid capacities of Ir-La-S/AC samples calibrated by $\mathrm{NH}_{3}$-TPD profiles are in the range $106.15-243.4 \mu \mathrm{mol} / \mathrm{g}$, which somewhat shows deviations from the data obtained by the acid-base-titration method. As shown in Fig. 9, both of the acid capacities data obtained by the two different methods show a clear linear relationship with the loading amount of sulfuric acid at $\mathrm{S}$ content lower than $20 \mathrm{wt} \%$.

\subsection{Carbonylation activities}

Evaluation results of methanol carbonylation over Ir-La/AC and Ir-La-S/AC catalysts with different $\mathrm{S}$ loading are listed in Table 4. The turn-over-frequency (TOF) of methanol carbonylation over Ir-La/AC catalyst was approximately $1000 \mathrm{~h}^{-1}$. The results on Ir-La-S/AC showed that the addition of S species to the catalysts enhanced the activity of methanol carbonylation.

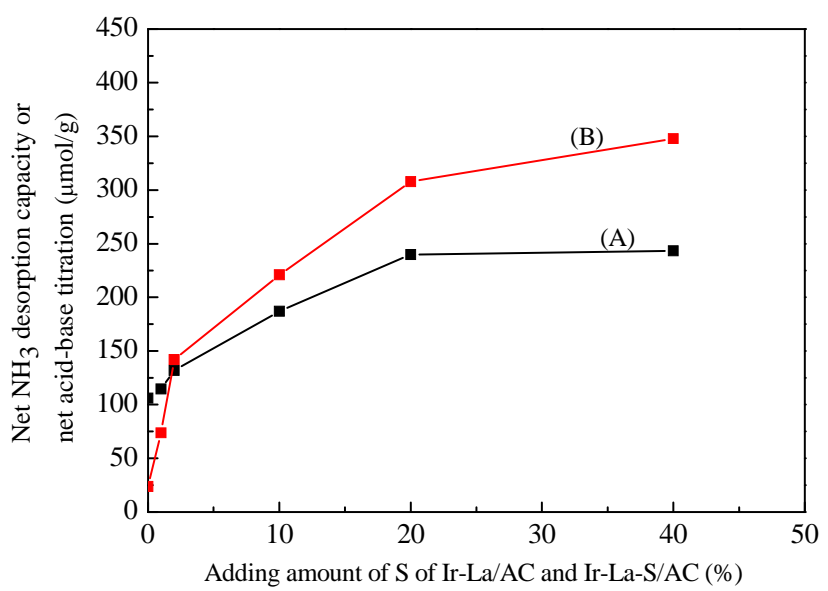

Fig. 9. Net $\mathrm{NH}_{3}$ desorption capacity vs. adding amount of $\mathrm{S}$ on Ir-La/AC and Ir-La-S/AC tested by $\mathrm{NH}_{3}$-TPD (A) and acid-base titration (B).

Table 4

The performance of Ir-La/AC and Ir-La-S/AC catalysts for heterogeneous vapor methanol carbonylation.

\begin{tabular}{lccccc}
\hline \multirow{2}{*}{ Catalyst } & Conversion & \multicolumn{3}{c}{ Selectivity (\%) } & TOF \\
\cline { 3 - 5 } & $(\%)$ & $\mathrm{CH}_{4}$ & $\mathrm{CH}_{3} \mathrm{COOH} \mathrm{CH}_{3} \mathrm{COOCH}_{3}$ & \multicolumn{1}{c}{$\mathrm{h}^{-1}$} \\
\hline Ir-La/AC & 40.4 & 4.57 & 2.1 & 93.39 & 1000 \\
Ir-La-1\%S/AC & 45.1 & 3.47 & 2.46 & 94.07 & 1100 \\
Ir-La-2\%S/AC & 60.41 & 2.62 & 5.11 & 92.27 & 1540 \\
Ir-La-10\%S/AC & 87.53 & 3.46 & 19.71 & 76.83 & 2600 \\
Ir-La-20\%S/AC & 90.26 & 3.66 & 23.96 & 72.38 & 2760 \\
Ir-La-40\%S/AC & 93.44 & 4.53 & 28.94 & 66.54 & 2873 \\
\hline
\end{tabular}

Reaction conditions: $0.21 \mathrm{~g}$ Ir-La/AC or Ir-La-S/AC catalyst (Ir $1 \mathrm{wt} \%$, La $0.7 \mathrm{wt} \%), F_{(\mathrm{CO} / \mathrm{H} 2=10: 1)}=34 \mathrm{~mL} / \mathrm{min}, F_{\text {liq }}\left(\mathrm{m}_{\text {Снзон: }}: \mathrm{m}_{\text {СнзІ }}=8: 1\right)=0.04$ $\mathrm{mL} / \mathrm{min}, \mathrm{LSVH}=6.5 \mathrm{~h}^{-1}, 235^{\circ} \mathrm{C}, 2.5 \mathrm{MPa}, \mathrm{TOS}=32 \mathrm{~h}$.

The TOF of Ir-La-1\%S/AC was slightly higher than that of Ir-La/AC, but an increase of $S$ content from 1 to $10 \mathrm{wt} \%$ led to a distinct increase of TOF from 1100 to $2600 \mathrm{~h}^{-1}$, and the selectivity to methyl acetate decreased from $94.07 \%$ to $76.83 \%$, accompanied by an increase of selectivity to acetic acid from $2.46 \%$ to $19.71 \%$, while the selectivity to methane remained almost unchanged. Further increase of S content from 10 to 40 wt \% resulted in a slight increase of TOF from 2600 to $2873 \mathrm{~h}^{-1}$, but the selectivity to acetic acid distinctly increased from $19.71 \%$ to $28.94 \%$.

The initial TOFs of methanol carbonylation over Ir-La/AC and Ir-La-20\%S/AC are shown in Fig. 10. The TOF of methanol

Table 3

Acid site density of AC, Ir-La/AC and Ir-La-S/AC catalysts tested by $\mathrm{NH}_{3}$-TPD and acid-base titration.

\begin{tabular}{lcccc}
\hline Catalyst & $\begin{array}{c}\text { Total } \mathrm{NH}_{3} \text { desorption } \\
\text { capacity }(\mu \mathrm{mol} / \mathrm{g})\end{array}$ & $\begin{array}{c}\mathrm{Net} \mathrm{NH}_{3} \text { desorption } \\
\text { capacity }(\mu \mathrm{mol} / \mathrm{g})\end{array}$ & $\begin{array}{c}\text { Acid-base titration }(0.01 \mathrm{~mol} / \mathrm{L} \\
\mathrm{NaOHaq})(\mu \mathrm{mol} / \mathrm{g})\end{array}$ & $\begin{array}{c}\text { Net acid-base titration }(0.01 \mathrm{~mol} / \mathrm{L} \\
\mathrm{NaOHaq})(\mu \mathrm{mol} / \mathrm{g})\end{array}$ \\
\hline $\mathrm{AC}$ & 49.04 & 0.00 & 36.2 & 0.00 \\
Ir-La/AC & 155.19 & 106.15 & 60 & 23.8 \\
Ir-La-1\%S/AC & 163.47 & 114.43 & 110 & 73.8 \\
Ir-La-2\%S/AC & 180.89 & 131.85 & 178 & 141.8 \\
Ir-La-10\%S/AC & 236.00 & 186.96 & 257 & 220.8 \\
Ir-La-20\%S/AC & 289.00 & 239.96 & 344 & 307.8 \\
Ir-La-40\%S/AC & 292.44 & 243.40 & 384 & 347.8 \\
Spent Ir-La-20\%S/AC & - & - & 274.65 & 238.45 \\
(TOS = 92 h) & - & &
\end{tabular}




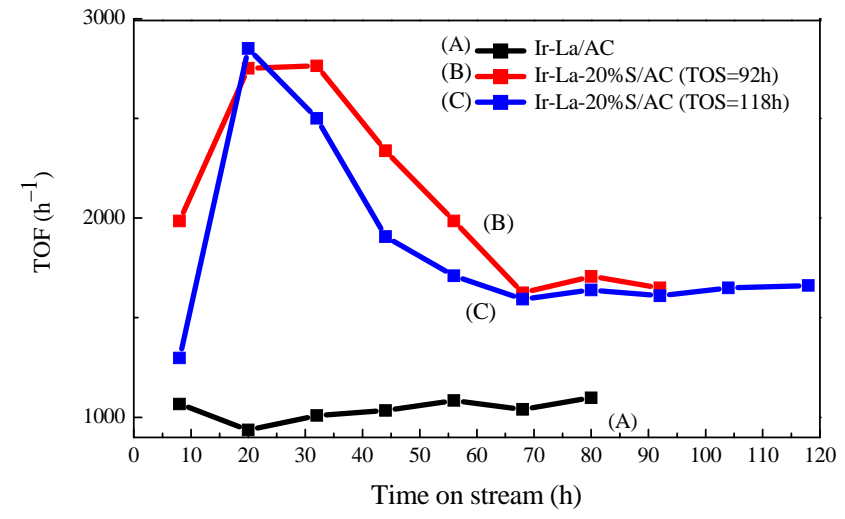

Fig. 10. Stability tests of Ir-La/AC and Ir-La-20\%S/AC catalysts for heterogeneous methanol carbonylation. Reaction conditions: $0.21 \mathrm{~g}$ Ir-La/AC or Ir-La-S/AC catalyst ( Ir $1 \mathrm{wt} \%$, La $0.7 \mathrm{wt} \%), F_{(\mathrm{CO} / \mathrm{H} 2=10: 1)}=34$ $\mathrm{mL} / \mathrm{min}, F_{\text {liq }}\left(\mathrm{m}_{\text {снзон: }} \mathrm{m}_{\text {снз }}=8: 1\right)=0.04 \mathrm{~mL} / \mathrm{min}, \mathrm{LSVH}=6.5 \mathrm{~h}^{-1}, 235^{\circ} \mathrm{C}$, $2.5 \mathrm{MPa}$.

\section{Table 5}

The amount of $\mathrm{Ir}$ and $\mathrm{La}$ in the collected liquid products of Ir-La-20\%S/AC methanol carbonylation process analyzed by ICP-MS and the theoretical loading amount of Ir and La in Ir-La-20\%S/AC.

\begin{tabular}{lcccc}
\hline \multirow{2}{*}{ Sample } & \multicolumn{2}{c}{ Ir } & \multicolumn{2}{c}{ La } \\
\cline { 2 - 5 } & $\begin{array}{c}\text { The amount } \\
\text { of Ir (g) }\end{array}$ & RSD & $\begin{array}{c}\text { The amount } \\
\text { of La (g) }\end{array}$ & RSD \\
\hline 0.5 g liquid products & $4.5 \times 10^{-9}$ & 8.3 & $1.05 \times 10^{-8}$ & 1.8 \\
Total liquid products & $2.1 \times 10^{-6}$ & & $4.8 \times 10^{-6}$ & \\
Ir-La-20\%S/AC $(0.21 \mathrm{~g})$ & $2.1 \times 10^{-3}$ & & $1.5 \times 10^{-3}$ & \\
\hline
\end{tabular}

carbonylation over Ir-La/AC maintained at approximately 1000 $\mathrm{h}^{-1}$ throughout the reaction test. The activity of Ir-La-20\%S/AC changed drastically during the initial $68 \mathrm{~h}$, and attained a maximum TOF value of $2760 \mathrm{~h}^{-1}$ at a TOS of $20 \mathrm{~h}$. The TOF decreased to $1660 \mathrm{~h}^{-1}$ at a time on stream (TOS) of $68 \mathrm{~h}$, but remained very stable during the remaining TOS from 68 to $118 \mathrm{~h}$. Table 5 shows that little Ir and La species of Ir-La-20\%S/AC was leached out during the methanol carbonylation process. Semi-quantitative analysis results of fresh and spent Ir-La-20\%S/AC catalysts (TOS $=92 \mathrm{~h}$ ) by XRF (X-ray fluorescence) in Table 6 illustrate that $S$ content decreased from 1.67 to $1.31 \mathrm{wt} \%$ during the initial period of $92 \mathrm{~h}$, which was supposed to be the key reason leading to the decline of TOF from approximately 2800 to $1660 \mathrm{~h}^{-1}$. However, the S content of spent Ir-La-20\%S/AC at a TOS of $118 \mathrm{~h}$ was $1.28 \%$, very similar to the $\mathrm{S}$ content at a TOS of $92 \mathrm{~h}$, which implies that the remaining S species were firmly attached on Ir-La-20\%S/AC, so

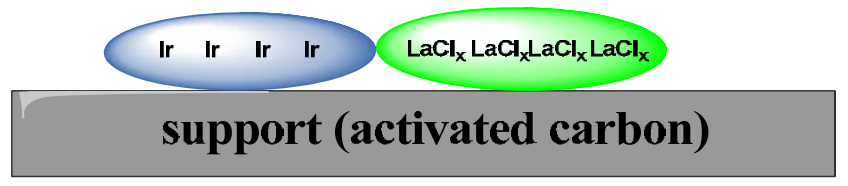

Ir-La/AC after treatment of $\mathrm{CO}: \mathrm{H}_{2}=10: 1$
Table 6

The semi-quantitative S content of fresh and spent Ir-La-20\%S/AC catalysts (TOS $=92$ and $118 \mathrm{~h}$ ).

\begin{tabular}{lc}
\hline Sample & The S content (wt\%) \\
\hline Fresh Ir-La-20\%S/AC & 1.67 \\
Spent Ir-La-20\%S/AC (92 h) & 1.31 \\
Spent Ir-La-20\%S/AC (118 h) & 1.28 \\
\hline
\end{tabular}

the catalyst achieved good stability as the reaction proceeded during the reaction test after reaching a TOS of $92 \mathrm{~h}$.

\subsection{Discussion}

The $\mathrm{H}_{2}$-TPR results confirm that the addition of a suitable amount of sulfuric acid to Ir-La-S/AC during the co-impregnation procedure favors the reduction of more I $^{3+}$ species to active states at a comparatively lower temperature. The data from in situ XPS demonstrates that more $\mathrm{Ir}^{3+}$ can be reduced to active $\mathrm{Ir}^{+}$over Ir-La-20\%S/AC than over Ir-La/AC under the same reaction conditions, which is thought to be beneficial for the reductive elimination of AcI from $\mathrm{Ir}^{3+}$ species as one of the essential elementary reaction steps during methanol carbonylation [34]. Furthermore, the HAADF-STEM measurements show that the components loaded on Ir-La-S/AC are dispersed better than those on Ir-La/AC. It is understandable that higher dispersity of loaded components makes it possible for more active $\mathrm{Ir}^{+}$sites to be exposed to the reactants, which would favor the reaction. HAADF-STEM measurements also show that most of the loaded components are located at single atomic sites over Ir-La-S/AC, as shown by the proposed models in Scheme 1, which might make the catalyst perform as efficiently as the corresponding homogeneous catalyst.

According to $\mathrm{NH}_{3}$-TPD and acid-base-titration results, it is concluded that the acidity of Ir-La-S/AC is distinctly enhanced by the addition of sulfuric acid during the co-impregnation procedure, and the acid sites of the catalyst are supposed to play a key role in CO insertion as the rate-determining step during the title reaction [34]. The XRF results indicate that the majority of the acidic $\mathrm{S}$ species is stable during the methanol carbonylation process, which is supposed to be in the form of $-\mathrm{SO}_{3} \mathrm{H}$ groups firmly attached to the surface of the AC carrier, as shown by the proposed models in Scheme 1. A small proportion of the acidic $\mathrm{S}$ species is supposed to be loaded as sulfates of $\mathrm{La}_{2}\left(\mathrm{SO}_{4}\right)_{3}$ and $\mathrm{IrCl}_{x}\left(\mathrm{SO}_{4}\right)_{y}$ species, which is easily replaceable by $\mathrm{I}^{-}$during the initial period of the reaction, leading to the decline of TOF from 2760 to $1660 \mathrm{~h}^{-1}$. The remaining $-\mathrm{SO}_{3} \mathrm{H}$
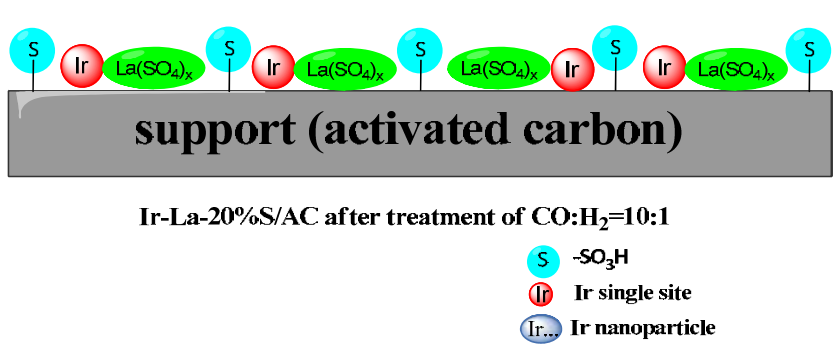

Scheme 1. The proposed dispersive models of Ir and La as well as acidic S species over the activated Ir-La/AC (A) and Ir-La-20\%S/AC (B) catalysts. 
groups firmly attached on the surface of the AC carrier are supposed to act as acidic promoters, similar to the role of $\mathrm{LaI}_{2(\mathrm{~S})}$ (subscript $\mathrm{S}$ = surface site of $\mathrm{AC}$ ), to enhance the activity of the single atomic active sites for $\mathrm{CO}$ insertion, which is thought to be the rate-limiting step as illustrated by the mechanism $[26,31,34]$. A negative effect of the strengthened acidity of the Ir-La-S/AC catalyst is that more water is produced as a by-product of the conversion of $\mathrm{MeOH}$ to methyl acetate (Eqs. (2) and (3)) as a result of the higher conversion rates, which favors the acid-catalyzed hydrolysis of methyl acetate, leading to obviously higher selectivity to acetic acid over the Ir-La-S/AC than that over the Ir-La/AC catalyst:

$$
\begin{aligned}
\mathrm{CH}_{3} \mathrm{OH}+\mathrm{CO} & \rightarrow \mathrm{CH}_{3} \mathrm{COOH} \\
\mathrm{CH}_{3} \mathrm{OH}+\mathrm{CH}_{3} \mathrm{COOH} & \rightarrow \mathrm{CH}_{3} \mathrm{COOCH}_{3}+\mathrm{H}_{2} \mathrm{O} \\
2 \mathrm{CH}_{3} \mathrm{OH}+\mathrm{CO} & \rightarrow \mathrm{CH}_{3} \mathrm{COOCH}_{3}+\mathrm{H}_{2} \mathrm{O}
\end{aligned}
$$

\section{Conclusions}

The introduction of sulfuric acidic groups into the Ir-La-S/AC catalyst is proved effective in promoting heterogeneous methanol carbonylation. The TOF of acetyl formation over Ir-La-S/AC was distinctly higher than that over unimproved Ir-La/AC catalyst. Unlike the $\mathrm{Ir}^{+}$species gathered as clusters or nanoparticles over the Ir-La/AC catalyst, the dominant forms of $\mathrm{Ir}^{+}$species over Ir-La-S/AC are verified as single atomic sites, which make Ir-La-S/AC catalysts perform more similarly to the corresponding efficient homogeneous catalysts. Most of the sulfuric acid added to the catalyst during the co-impregnation procedure is firmly attached to the surface of the carrier, and the acidity of the $\mathrm{S}$ species can also act as a promoter to accelerate the $\mathrm{CO}$ insertion step of methanol carbonylation. Ir-La-S/AC represents an alluring prospect for re- ducing environmental pollution and device corrosion caused by the usage of liquid acid and for solving the problem of the cyclic utilization of liquid Ir-based catalysts, which are features that exist in the corresponding homogeneous system.

\section{References}

[1] S. F. Ji, Y. J. Chen, Q. Fu, Y. F. Chen, J. C. Dong, W. X. Chen, Z. Li, Y. Wang, L. Gu, W. He, C. Chen, Q. Peng, Y. Huang, X. F. Duan, D. S. Wang, C. Draxl, Y. D. Li, J. Am. Chem. Soc., 2017, 139, 9795-9798.

[2] S. Mukhopadhyay, R. J. Staples, W. H. Armstrong, Chem. Commun., 2002, 864-865.

[3] M. Li, S. J. Wu, X. Y. Yang, J. Hu, L. Peng, L. Bai, Q. S. Huo, J. Q. Guan, Appl. Catal. A, 2017, 543, 61-66.

[4] W. G. Liu, L. L. Zhang, W. S. Yan, X. Y. Liu, X. F. Yang, S. Miao, W. T. Wang, A. Q. Wang, T. Zhang, Chem. Sci., 2016, 7, 5758-5764.

[5] B. T. Qiao, J. X. Liang, A. Q. Wang, J. Y. Liu, T. Zhang, Chin. J. Catal., 2016, 37, 1580-1587.

[6] J. X. Liang, X. F. Yang, C. Q. Xu, T. Zhang, J. Li, Chin. J. Catal., 2017, 38, 1566-1573.

[7] M. Jiang, L. Yan, Y. J. Ding, Q. Sun, J. Liu, H. J. Zhu, R. H. Lin, F. S. Xiao, Z. Jiang, J. Y. Liu, J. Mol. Catal. A, 2015, 404, 211-217.

[8] B. T. Qiao, A. Q. Wang, X. F. Yang, L. F. Allard, Z. Jiang, Y. T. Cui, J. Y. Liu, J. Li, T. Zhang, Nat. Chem., 2011, 3, 634-641.

[9] A. W. Budiman, J. S. Nam, J. H. Park, R. I. Mukti, T. S. Chang, J. W. Bae, M. J. Choi, Catal. Surv. Asia, 2016, 20, 173-193.

[10] M. J. Howard, M. D. Jones, M. S. Roberts, S. A. Taylor, Catal. Today, 1993, 18, 325-354.

[11] C. Poonjarernsilp, N. Sano, H. Tamon, Appl. Catal. B, 2014, 147, 726-732.

[12] A. Onda, T. Ochi, K. Yanagisawa, Top. Catal., 2009, 52, 801-807.

[13] F. Peng, L. Zhang, H. J. Wang, P. Lv, H. Yu, Carbon, 2005, 43, 2405-2408.

[14] Z. Hajamini, M. A. Sobati, S. Shahhosseini, B. Ghobadian, Appl.

\section{Graphical Abstract}

Chin. J. Catal., 2018, 39: 1060-1069 doi: 10.1016/S1872-2067(18)63019-0

\section{Acid-promoted Ir-La-S/AC-catalyzed methanol carbonylation on single atomic active sites}

Zhou Ren, Yuan Lyu *, Siquan Feng, Xiangen Song, Yunjie Ding *

Dalian Institute of Chemical Physics, Chinese Academy of Sciences; University of Chinese Academy of Sciences

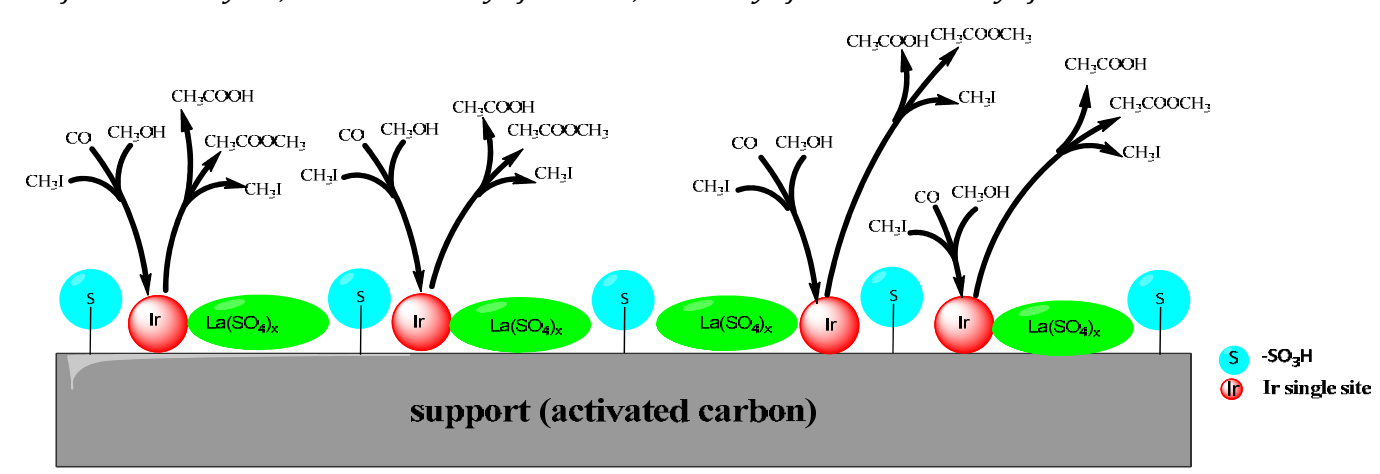

Ir-La-20\%S/AC for methanol carbonylation

By addition of S species, the acid-promoted single-site Ir-La-S/AC catalyst, which displayed much high activity of carbonylation, was successfully prepared by co-impregnation method and applied in vapor-phase heterogeneous carbonylation of methanol. 
Therm. Eng., 2016, 94, 141-150.

[15] J. F. Chen, Y. R. Zhang, L. Tan, Y. Zhang, Ind. Eng. Chem. Res., 2011, $50,4212-4215$.

[16] B. Wang, J. F. Chen, Y. Zhang, RSC Adv., 2015, 5, 22300-22304.

[17] R. L. Lu, D. S. Mao, J. Yu, Q. S. Guo, J. Ind. Eng. Chem., 2015, 25, 338-343.

[18] B. T. Li, X. Y. Qian, X. J. Wang, Int. J. Hydrogen Energy, 2015, 40, 8081-8092.

[19] Z. P. Qu, W. X. Huang, S. T. Zhou, H. Zheng, X. M. Liu, M. J. Cheng, X. H. Bao, J. Catal., 2005, 234, 33-36.

[20] L. H. Shi, D. B. Li, B. Hou, Y. L. Wang, Y. H. Sun, Fuel Process. Technol., 2010, 91, 394-398.

[21] D. H. Jiang, Y. J. Ding, Z. D. Pan, W. M. Chen, H. Y. Luo, Catal. Lett., 2008, 121, 241-246.

[22] Y. Zhang, K. Hanayama, N. Tsubaki, Catal. Commun., 2006, 7, 251-254.

[23] S. W. Ho, Y. S. Su, J. Catal., 1997, 168, 51-59.

[24] D. F. R. Mildner, J. M. Carpenter, J. Non-Cryst. Solids, 1982, 47, 391-402.

[25] A. Riisager, B. Jorgensen, P. Wasserscheid, R. Fehrmann, Chem. Commun., 2006, 994-996.

[26] A. Haynes, Top. Organomet. Chem. 2006, 18, 179-205.

[27] J. H. Jones, Platinum Metals Rev., 2000, 44, 94-105.

[28] K. Cheng, B. Gu, X. L. Liu, J. C. Kang, Q. H. Zhang, Y. Wang, Angew. Chem. Int. Ed., 2016, 55, 4725-4728.

[29] Y. C. Shi, E. H. Xing, K. J. Wu, J. L. Wang, M. D. Yang, Y. L. Wu, Catal. Sci. Technol., 2017, 7, 2385-2415.

[30] A. Haynes, D. J. Law, A. Miller, G. E. Morris, M. J. Payne, J. G. Sunley, WO 2005009939, 2005.

[31] A. Haynes, Adv. Catal., 2010, 53, 1-45.
[32] G. J. Sunley, D. J. Watson, Catal. Today, 2000, 58, 293-307.

[33] P. M. Maitlis, A. Haynes, G. J. Sunley, M. J. Howard, J. Chem. Soc. Dalton Trans., 1996, 2187-2196.

[34] J. H. Kwak, R. Dagle, G. C. Tustin, J. R. Zoeller, L. F. Allard, Y. Wang, J. Phys. Chem. Lett., 2014, 5, 566-572.

[35] J. R. Zoeller, A. H. Singleton, G. C. Tustin, D. L. Carver, US 6,159,896, 2000.

[36] J. R. Zoeller, A. H. Singleton, G. C. Tustin, D. L. Carver, US 6,137,000, 2000.

[37] W. T. Luo, Y. Lyu, L. F. Gong, H. Du, T. Wang, Y. J. Ding, RSC Advances, 2016, 6, 13600-13608.

[38] W. T. Luo, Y. Lyu, L. F. Gong, H. Du, M. Jiang, Y. J. Ding, Reac. Kinet. Mech. Cat., 2016, 118, 481-496.

[39] J. R. Kastner, J. Miller, D. P. Geller, J. Locklin, L. H. Keith, T. Johnson, Catal. Today, 2012, 190, 122-132.

[40] X. M. Zhang, Y. P. Zhao, S. T. Xu, Y. Yang, J. Liu, Y. X. Wei, Q. H. Yang, Nat. Commun., 2014, 5, 4170/1-4170/9.

[41] C. W. Wang, X. Gui, Z. Yun, Reac. Kinet. Mech. Cat., 2014, 113, 211-223.

[42] A. Eitan, K. Y. Jiang, D. Dukes, R. Andrews, L. S. Schadler, Chem. Mater., 2003, 15, 3198-3201.

[43] J. Gao, Z. Y. Hou, J. Z. Guo, Y. H. Zhu, X. M. Zheng, Catal. Today, 2010, 151, 412-412.

[44] J. F. Moulder, W. F. Stickle, P. E. Sobol, K. D. Bomben, Handbook of $X$-Ray Photoelectron Spectroscopy, Pekin-Elmer, Eden Prairie, 1992.

[45] M. Hara, T. Yoshida, A. Takagaki, T. Takata, J. N. Kondo, S. Hayashi, K. Domen, Angew. Chem. Int. Ed., 2004, 43, 2955-2958.

[46] M. X. Zhao, X. Y. Wei, Z. M. Zong, Chin. J. Catal., 2016, 37, 1324-1330.

\title{
基于酸促进的单原子活性位点Ir-La-S/AC催化剂 在甲醇羰基化中的应用
}

\author{
任 周a,c, 吕 元 ${ }^{\mathrm{a}, *}$, 冯四全 ${ }^{\mathrm{a}, \mathrm{c}}$, 宋宪根, 丁云杰, ${ }^{\mathrm{a}, \mathrm{b}, \#}$ \\ a 中国科学院大连化学物理研究所洁净能源国家实验室, 辽宁大连 116023 \\ $\mathrm{b}^{\mathrm{b}}$ 中国科学院大连化学物理研究所催化基础国家重点实验室, 辽宁大连116023 \\ c中国科学院大学, 北京100049
}

摘要: 甲醇羰基化是世界上重要的均相催化反应之一. 无论是 $R h$ 或者 $I r$ 体系, 虽然碘甲烷的引入会带来腐蚀问题, 但是绝 大多数的甲醇羰基化反应过程都需要碘甲烷作为助催化剂才能有较好的活性. 多年来人们在不断研究非均相羰基化过程 (即均相多相化), 以避免均相中间歇生产和产物分离的缺点. 其中 Ir体系的非均相羰基化报道很少, 值得关注的是 Eastman公司将Ir-La/AC体系成功地应用于非均相的甲醇羰基化过程. 基于此, 本文试图引入硫元素以提高Ir-La/AC催化剂 的羰基化活性, 即将含有 La和Ir前驱体的硫酸溶液通过共浸渍法制备了高活性的Ir-La-S/AC催化剂, 评价了该系列催化剂 的性能, 并进行了深入的表征. Ir-La-S/AC 催化剂的 TOF 最高可达 $2760 \mathrm{~h}^{-1}$, 远远高于 Ir-La/AC 催化剂 $1000 \mathrm{~h}^{-1}$. HAADF-STEM的结果表明,Ir-La-S/AC催化剂中Ir物种绝大多数处于单分散状态, 而Ir-La/AC催化剂中的Ir物种为平均粒径 为 $1.5 \mathrm{~nm}$ 的纳米颗粒状态, 说明Ir-La-S/AC催化剂中Ir的使用效率要远远高于Ir-La/AC. 其次, $\mathrm{NH}_{3}-\mathrm{TPD}$ 的结果显示在制备 过程中硫酸的加入使催化剂的酸性位点大幅度增多, 而酸性位可以加速Ir体系机理中CO插入这一决速步骤. 目前普遍认

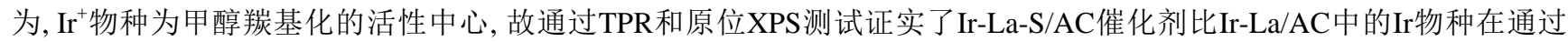

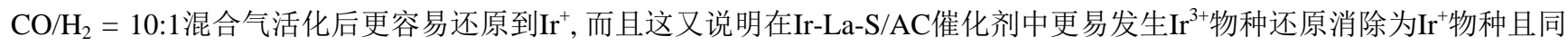
时产生酰基碘（AcI）这一重要循环步骤. 所以Ir-La-S/AC催化剂具有更多的酸促进位点, 更高的Ir分散度和更多的 Ir 活性 物种. 此外, Ir-La-S/AC催化剂的羰基化活性在 $66 \mathrm{~h}$ 之后才趋于稳定 $\left(1660 \mathrm{~h}^{-1}\right)$, 通过XRF测试发现该过程中有少量的硫流 失, 而大部分剩余的硫比较稳定的存在于催化剂表面, 且通过ICP-MS结果显示Ir和La没有明显的流失, 因此66 h 之前活性 
下降主要是由于部分 $\mathrm{S}$ 的流失, 而不是金属物种 $\mathrm{Ir}$ 和 $\mathrm{La}$ 流失造成的. 总之, 我们成功地制备了一种硫促进的双功能 Ir-La-S/AC催化剂, 这种方法不仅减轻了由液体酸带来的环境污染和设备腐蚀, 同时避免了液相铱体系催化剂的循环使用 问题.

关键词: 非均相甲醇羰基化; Ir-La-S/AC催化剂; 双功能催化剂; 单分散活性位点; 共浸渍

收稿日期: 2018-01-19. 接受日期: 2018-03-02. 出版日期: 2018-06-05.

*通讯联系人. 电话: (0411)84379601; 传真: (0411)84379143; 电子信箱: luyuan@dicp.ac.cn

\#通讯联系人. 电话/传真: (0411)84379143; 电子信箱: dyj@dicp.ac.cn

基金来源：国家重点研发计划 (2017YFB0602203).

本文的电子版全文由Elsevier出版社在ScienceDirect上出版(http://www.sciencedirect.com/science/journal/18722067). 